\title{
From the Editor: Toward an Interdisciplinary Approach
}

\author{
Jing Jian Xiao
}

Published online: 27 November 2008

(C) Springer Science+Business Media, LLC 2008

The mission of Journal of Family and Economic Issues is to publish original research papers and critical literature reviews that address important family economic issues to improve family well-being. As the editor, I tried my best to be inclusive and open to researchers from all relevant fields. Among authors who wrote for JFEI, some are from root discipline departments, such as economics, psychology, sociology, etc., and others are from multidisciplinary or interdisciplinary departments, such as business, consumer science, family studies, human development, social work, etc. Also more and more papers in recent JFEI issues are contributed by researchers who reside outside of the U.S. For a 20-year review of themes and trends of JFEI, see Dew (2008). To address complex family economic issues and find realistic solutions, we need contributions of researchers from diverse fields. In the next a few years, I would like to see more research papers using interdisciplinary approaches and critical literature reviews from interdisciplinary perspectives.

As the editor, I greatly appreciate assistance from the editorial board members and ad hoc reviewers for their constructive suggestions and comments on manuscripts submitted to Journal of Family and Economics Issues. Their efforts contribute to the high quality of this journal. In addition, special thanks go to two people for their services as guest-editors for two thematic issues: Lucia F. Dunn at the Ohio State University for the June 2008 issue on consumer financial issues and Jr-Tsung Huang at the National Chengchi University in Taiwan for the December 2008 issue on family economic issues in Asia and U.S. I

J. J. Xiao $(\bowtie)$

Transition Center, University of Rhode Island, Kingston,

RI 02881, USA

e-mail: jfei.editor@gmail.com also thank Vicki Fitzsimmons, Brian Haroldson and Grace Hedstrom for their excellent assistance in copyediting. The following is a list of reviewers who reviewed manuscripts from September 2007 to October 2008:

Douglass Abbott
Mohamed Abdel-Ghany
Myria Allen
Elaine Anderson
Joan Gray Anderson
Mary Arends-Kuenning
Nan Marie Astone
Bill Bailey
Burt Barnow
Suzanne Bartholomae
Ann Berry
Ivan Beutler
Vibha Bhargava
Lynne Borden
Ann Buchanan
Yi Cai
Wendy Campione
Honggao Cao
Richard Caputo
Aihwa Chang
Yunhee Chang
Jenniou Chen
Zhuo Chen
Hwei-Lin Chuang
Michael Collins
Stephen Cosslett
Lyn Craig
Karla Damino-Teixeira
Sharon Danes
Kathrine Daniels


Laura DeHaan

Enilda Delgado

Jeff Dew

Jennie Dilworth

Elizabeth Dolan

Qingwen Dong

Diana Doumas

Martin Dribe

Marta Elliot

Sarah Beth Estes

Jessie Fan

Mike Finke

Margaret Fitzgerald

Cindy Fletcher

Steve Garasky

Inmaculada Garcia

Tom Garman

Stephen Giyma

Elizabeth Goldsmith

John Grable

Irina Grafova

Sue Greninger

Yung-Hsing Guo

Clinton Gudmunson

Shelley Haddock

Muhammad Haj-Yahia

Scott Hall

Chang-Keun Han

Sherman Hanna

Donald Haurin

Celia Hayhoe

George Haynes

Claudia Heath

Charles Hennon

Twyla J. Hill

Tahira Hira

Jeanne Hogarth

Karen Anderson Holden

Gong-soog Hong

Mei Hsu

Jr-Tsung Huang

Phyllis Johnson

Alison Jones

Hyungsoo Kim

Elizabeth Kiss

Ralph Kober

Jane Kolodinsky

Karen Kopera-Frye

Chun-Chien Kuo

Christine W. Lai

Hee-Sook Lee

Ho Jin Lee

Sun-A Lee
Yoon Lee

Haifeng Li

Tsui-Fang Lin

Michelle Livermore

Vance Lo

Csazilia Loibl

Tom Lucey

Shelly Lundberg

Kevin Lyness

Angela Lyons

Maurice MacDonald

Lakshmi Malroutu

Elizabeth Maring

Peter Martin

Marshall Medoff

Sue McGregor

Yoko Mimura

Ida Mirzaie

Alberto Molina

Jason Murasko

Glenn Muske

Barbara Newman

Robert Nielsen

Ikuko Ogawa

Brett O'Hara

Barbara O'Neill

Pam Olson

Anna Paulson

Arianto Patunru

Martina Peng

Robert Perrucci

Candace Philbrick

Gregory Ponthiere

Karen Randolph

Kathryn Rettig

Sherrie Rhine

Paul Rivera

Kathleen Roche

Rose Rubin

David Schramm

Joyce Serido

Jennifer Shand

Deanna Sharpe

Catherine Solheim

Maria Stanfors

Susan Stewart

Jo Swanson

Akinori Tomohara

Eileen Trzcinski

Jean Wallace

Cong Wang

Jennifer Ward-Batts

Richard Widdows 
Shih-Ying Wu

Terry Yan

Kaili Yieh

Tansel Yilmazer

Baomei Zhao

Cathleen Zick

\section{References}

Dew, J. (2008). Themes and trends of Journal of Family and Economic Issues: A review of twenty years (1988-2007). Journal of Family and Economic Issues, 29, 496-541. 